\title{
Heterotrophic enzymatic biotransformations of organic micropollutants in activated sludge
}

\author{
David M. Kennes-Veiga ${ }^{\mathrm{a}, *}$, Bernadette Vogler $^{\mathrm{b}}$, Kathrin Fenner ${ }^{\text {b,c,d }}$, Marta Carballa ${ }^{\mathrm{a}}$, Juan M. Lema ${ }^{\mathrm{a}}$ \\ a Cretus Institute, Department of Chemical Engineering, Universidade de Santiago de Compostela, 15782 Santiago de Compostela, Galicia, Spain \\ b Swiss Federal Institute of Aquatic Science and Technology, Eawag, 8600 Dübendorf, Switzerland \\ c Institute of Biogeochemistry and Pollutant Dynamics, ETH Zürich, 8092 Zürich, Switzerland \\ d Department of Chemistry, University of Zürich, 8057 Zürich, Switzerland
}

\section{H I G H L I G H T S}

- Aerobic heterotrophs proved their capacity to extensively biotransform OMPs.

- Biotransformation was similar to that of activated sludge with nitrogen removal.

- Oxidation, hydrolysis and conjugation were identified as relevant mechanisms.

- Oxygenases, dehydrogenases, hydrolases and transferases appear to play a key role.

\section{A R T I C L E I N F O}

\section{Article history:}

Received 14 December 2020

Received in revised form 16 February 2021

Accepted 14 March 2021

Available online 18 March 2021

Editor: Paola Verlicchi

\section{Keywords:}

Cometabolism

Enzymes

Heterotrophs

Pharmaceuticals

Transformation products

Wastewater
G R A P H I C A L A B S T R A C T

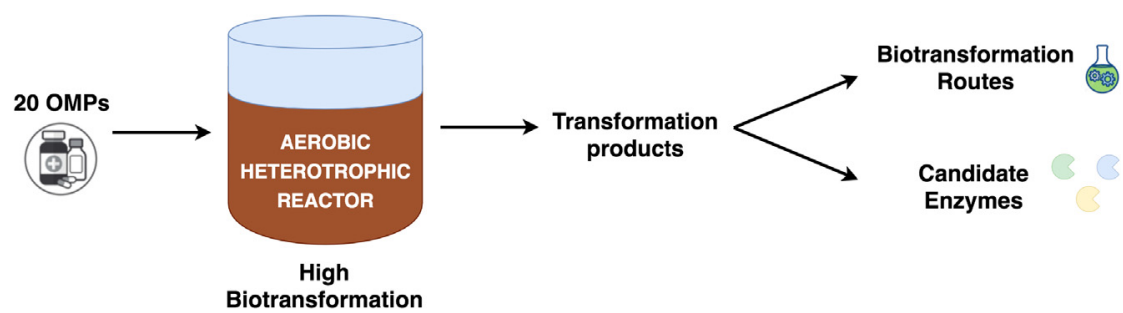

\begin{abstract}
A B S T R A C T
While heterotrophic microorganisms constitute the major fraction of activated sludge biomass, the role of heterotrophs in the biotransformation of organic micropollutants (OMPs) has not been fully elucidated. Yet, such knowledge is essential, particularly when conceiving novel wastewater treatment plants based on a two-stage process including an A-stage under heterotrophic conditions and a B-stage based on anammox activity. Biotransformation of OMPs in activated sludge is thought to mostly occur cometabolically thanks to the action of low specificity enzymes involved in the metabolism of the primary substrates. For a better understanding of the process, it is important to determine such enzymatic activities and the underlying mechanisms involved in OMPs biotransformation. This task has proven to be difficult due to the lack of information about the enzymatic processes and the complexity of the biological systems present in activated sludge. In this paper, a continuous aerobic heterotrophic reactor following 20 OMPs at environmental concentrations was operated to $(i)$ assess the potential of heterotrophs during the cometabolic biotransformation of OMPs, (ii) identify biotransformation reactions catalyzed by aerobic heterotrophs and (iii) predict possible heterotrophic enzymatic activities responsible for such biotransformations. Contradicting previous reports on the dominant role of nitrifiers in OMPs removal during activated sludge treatment, the heterotrophic population proved its capacity to biotransform the OMPs to extents equivalent to reported values in nitrifying activated sludge plants. Besides, 12 transformation products potentially formed through the activity of several enzymes present in heterotrophs, including monooxygenases, dioxygenases, hydrolases and transferases, were identified.
\end{abstract}

(c) 2021 Elsevier B.V. All rights reserved.

\footnotetext{
* Corresponding author.

E-mail address: david.kennes@usc.es (D.M. Kennes-Veiga).
}

\section{Introduction}

Activated sludge systems are designed to reduce the biological oxygen demand and the concentration of nutrients, such as nitrogen and phosphorous, in wastewaters. However, they are also capable to remove organic micropollutants (OMPs) such as pharmaceuticals, personal care 
products and pesticides that reach wastewater treatment plants (WWTPs) through surface runoff and sewers (Besha et al., 2017; Fischer and Majewsky, 2014). The removal efficiency of OMPs in activated sludge systems depends on the nature of the compounds, the operational parameters, the properties of the wastewater and the characteristics of the microbial community (Achermann et al., 2018b).

Most studies on activated sludge systems include heterotrophic and nitrifying activities and provide extensive information on OMPs biotransformation (Lambropoulou and Nollet, 2014; Lema and Suarez, 2017). Moreover, it has repeatedly been shown that nitrifying activity enhances or is even required for substantial biotransformation of many OMPs (Fernandez-Fontaina et al., 2012; Helbling et al., 2012; Tran et al., 2009). As a consequence, it is widely assumed, and for some compounds also experimentally proven, that nitrifiers play a key role in biotransformation. Yet, there are still only a few studies that investigate the specific role the different microbial populations play (Alvarino et al., 2018; Khunjar et al., 2011; Margot et al., 2016; Men et al., 2017), and, in particular, that of the heterotrophic population. At the same time, the heterotrophic activity is gaining interest due to novel WWTPs conceptions, where the Astage, operating with high loadings and low solid retention times (SRT), exclusively converts readily degradable organic matter, whereas the B-stage is proposed to be operated by an anammox consortium (Liu et al., 2020).

The main removal mechanism for many water-borne OMPs is microbial biotransformation, which is assumed to be of cometabolic nature mostly, due to the very low concentrations at which OMPs are present in wastewater, i.e., in the $\mu$ g to $\mathrm{ng} \mathrm{L}^{-1}$ range (Luo et al., 2014; Petrie et al., 2014). Under these conditions, OMPs can hardly provide enough energy to support cellular growth and maintenance and are hence most likely biotransformed by enzymes involved in the biodegradation of primary substrates, which are present at considerably higher concentrations (Alvarino et al., 2018). In activated sludge systems, such enzymes are present in the metabolic network of aerobic nitrifiers and heterotrophs. In the case of nitrifiers, they use simple and well-known substrates, presenting a limited number of candidate enzymes potentially involved in OMPs biotransformation, which facilitates the development of studies trying to elucidate their role. For example, ammonia monooxygenases, present in ammonia-oxidizing bacteria (AOB) and archaea (AOA), have been recognised as key in OMPs biotransformation due to their low substrate specificity (FernandezFontaina et al., 2016; Margot et al., 2016; Rasche et al., 1990; Yi and Harper, 2007), while enzymes of other nitrifying populations, such as nitrite-oxidizing bacteria, have shown a less relevant contribution to the biotransformation of OMPs (Fernandez-Fontaina et al., 2016; Yu et al., 2018). In contrast, aerobic heterotrophs can use a wide variety of organic substrates, sometimes very complex and with different physicochemical properties, which leads to a huge number of candidate enzymes that could contribute to OMPs biotransformation (Achermann et al., 2020; Fischer and Majewsky, 2014; Gulde et al., 2016; Krah et al., 2016). This complexity has resulted in very few studies trying to determine the key enzymes involved in the heterotrophic breakdown of OMPs, despite acknowledging that the heterotrophic biomass governs or enhances the cometabolic removal of many compounds, such as aminopolycarboxylic acids, sulfamethoxazole, diclofenac, paracetamol and 17- $\alpha$-ethinylestradiol (Kennes-Veiga et al., 2020; Larcher and Yargeau, 2013; Majewsky et al., 2011, 2010; Tran et al., 2009). Furthermore, it has been reported that heterotrophs and autotrophs can cooperate to remove OMPs and attenuate the presence of intermediate transformation products (TPs). For instance, it has been hypothesized that without an active fraction of heterotrophic biomass, intermediates of estrogens would accumulate in AOB cultures (Shi et al., 2004; Yi and Harper, 2007). Therefore, understanding the capabilities of the heterotrophic population is important even when both nitrifiers and heterotrophs are capable of biotransforming the same compounds because they may perform the biotransformation at different rates and/or follow pathways that lead to distinctly different TPs (Fischer and Majewsky, 2014).

Since OMPs are frequently not fully mineralized during cometabolic biotransformation, the assessment of the TPs is also important because they pose the potential to be as or even more toxic than their parent compounds to the ecosystem (Berkner and Thierbach, 2014; Celiz et al., 2009; Gulde et al., 2016). Besides, TPs identification can be a very helpful tool to determine the reactions occurring in a specific environment and provide hints about the enzymatic activities catalyzing OMPs biotransformation. For instance, following this approach, Gulde et al. (2016) demonstrated that $\mathrm{N}$-acyltransferases could be involved in the biotransformation of several amine-containing OMPs in activated sludge.

In this study, we aim to address the contribution of heterotrophs to the biotransformation of OMPs in activated sludge processes and, particularly, their capacity to biotransform a range of OMPs. Besides, we attempt to detect several TPs as a tool to identify key OMP biotransformation reactions catalyzed by aerobic heterotrophs and decipher possible enzymatic activities carrying out such biotransformations. To this end, we evaluated the biotransformation of a set of OMPs with different physicochemical properties in an aerobic heterotrophic reactor and used liquid chromatography coupled to high-resolution mass spectrometry to identify TPs.

\section{Materials and methods}

\subsection{Continuous aerobic heterotrophic reactor}

A $5 \mathrm{~L}$ continuously stirred lab-scale reactor, connected to a $2 \mathrm{~L}$ settler, was operated at $25^{\circ} \mathrm{C}$. The reactor was inoculated with sludge from an activated sludge reactor of a WWTP near Santiago de Compostela (Spain) and aerated to ensure oxygen concentrations around 6-7 $\mathrm{mg} \mathrm{O}_{2} \mathrm{~L}^{-1}$. The feeding consisted of a synthetic mixture of sodium acetate/acetic acid (in concentrations that ensured operation at neutral $\mathrm{pH}$ ), ammonium chloride, potassium dihydrogen phosphate, calcium chloride and magnesium sulfate (Table S1). Also, other trace nutrients were added to promote the growth of the aerobic heterotrophic microorganisms (Table S2). The hydraulic retention time (HRT) was set to $1 \mathrm{~d}$ and the organic loading rate (OLR) to $0.6 \mathrm{~g}$ chemical oxygen demand (COD) $\mathrm{L}^{-1} \mathrm{~d}^{-1}$. To avoid nitrification, the SRT was kept below 8 days and allylthiourea (ATU) was added to the feeding at a concentration of $5 \mathrm{mg} \mathrm{L}^{-1}$.

The operation of the aerobic heterotrophic reactor was monitored measuring the total suspended solids (TSS), volatile suspended solids (VSS), total and soluble $\mathrm{COD}$, ammonium $\left(\mathrm{NH}_{4}^{+}\right)$, nitrate $\left(\mathrm{NO}_{3}^{-}\right)$, nitrite $\left(\mathrm{NO}_{2}^{-}\right)$and oxygen concentrations, $\mathrm{pH}$ and temperature according to Standard Methods (Rice et al., 2012). The measurements were performed in triplicate twice per week. Moreover, after four weeks of operation, the changes in OMPs levels and the emergence of potential TPs was determined by taking samples in triplicate from the inlet and outlet of the reactor (considering both the liquid and solid phase) for one week.

\subsection{Organic micropollutants}

This study focused on 20 environmentally relevant compounds commonly present in wastewater that cover a wide variety of functional groups, physicochemical properties and applications. The compounds were: the antibiotics erythromycin (ERY), roxithromycin (ROX), trimethoprim (TMP), sulfamethoxazole (SMX); the anti-inflammatories ibuprofen (IBP), naproxen (NPX), diclofenac (DCF); the neurodrugs carbamazepine (CBZ), diazepam (DZP), fluoxetine (FLX); the biocide triclosan (TCS); the musk fragrances celestolide (ADBI), galaxolide (HHCB), tonalide (AHTN); the endocrine disruptors estrone (E1), 17ßestradiol (E2), 17 $\alpha$-ethinylestradiol (EE2) and the xenoestrogens bisphenol A (BPA), 4-octylphenol (OP) and 4-nonylphenol (NP). The OMPs were purchased from Sigma-Aldrich (Germany), except for the musk fragrances, which were acquired from Ventos (Spain). Depending on the substance, stock solutions were prepared in HPLC-grade acetone 
or methanol and stored at $-20^{\circ} \mathrm{C}$. They were added to the feeding at a concentration of $10 \mu \mathrm{g} \mathrm{L}^{-1}$, except for the musk fragrances and hormones, whose concentrations were 40 and $1 \mu \mathrm{g} \mathrm{L}^{-1}$, respectively.

\subsection{Chemical analysis of the OMPs}

Influent and effluent samples were centrifuged at $3500 \mathrm{rpm}$ for $10 \mathrm{~min}$. The supernatant was prefiltered (AP4004705, Millipore) and then filtered again at $0.45 \mu \mathrm{m}$ (HAWP04700, Millipore). Then, solid phase extraction (SPE) was performed with $200 \mathrm{~mL}$ samples and $60 \mathrm{mg}$ Oasis HLB cartridges (Waters, Milford, MA, USA), as described by Fernandez-Fontaina et al. (2013). The quantification of antibiotics (ERY, ROX, SMX, TMP), neurodrugs (FLX, CBZ, DZP) and hormones (E1, E2, EE2) was performed using an Agilent G1312A liquid chromatography instrument with a binary pump and automatic injector HTCPAL (CTC Analytics) connected to a mass spectrometer API 4000 triple quadrupole (Applied Biosystems). Musk fragrances (HHCB, AHTN, ADBI), anti-inflammatories (IBP, NPX, DCF), xenoestrogens (BPA, OP, NP) and the biocide (TCS) were quantified using gas chromatography (Varian CP-3900) coupled to an ion trap spectrometer (Varian CG2100 ). The quantification procedure was done according to previous studies (Alvarino et al., 2014). All OMPs analyses were performed in triplicate.

The solid phase was frozen and lyophilized. To quantify the OMPs sorbed onto the aerobic sludge, ultrasonic solvent extraction (USE) was performed (Ternes et al., 2005). The USE technique consisted of three sequential extractions with methanol and two with acetone applied to freeze-dried samples of approximately $0.5 \mathrm{~g}$. During each extraction, the samples were sonicated for $15 \mathrm{~min}$ and centrifugated at $1500 \mathrm{rpm}$ for $5 \mathrm{~min}$. Then, the supernatants were combined, filtered through glass wool, evaporated (R-205, Büchi) under vacuum conditions (150 mbar) at $35{ }^{\circ} \mathrm{C}$ and diluted with distilled water. Finally, SPE and micropollutant quantification was performed as described for the liquid phase.

\subsection{Chemical analysis of the transformation products}

To detect TPs, the samples were again analysed using reversedphase liquid chromatography coupled to a high-resolution quadrupole Orbitrap mass spectrometer ( $\mathrm{Q}$ Exactive or Q Exactive Plus, Thermo Scientific). Full-scan MS spectra were acquired both in positive and negative ionization modes and the acquisition of MS2 fragmentation spectra was triggered at $\mathrm{m} / \mathrm{z}$ values corresponding to masses of suspected TPs.

The sample was loaded onto an Atlantis T3 column (particle size $3 \mu \mathrm{m}, 3.0 \times 150 \mathrm{~mm}$, Waters) equipped with a guard column (Atlantis T3 VanGuard Cart $3 \mu \mathrm{m}, 3.9 \times 5 \mathrm{~mm}$ ). Nanopure water (Barnstead Nanopure, Thermo Scientific) and methanol (HPLC grade, Fischer Scientific), both with $0.1 \%$ formic acid (98-100\%, Merck), were used as mobile phase at a flow rate of $300 \mu \mathrm{L} \mathrm{min}^{-1}$. Initial conditions (95:5 water/methanol) were maintained for $1 \mathrm{~min}$ and then the methanol fraction increased over 16 min to 5:95 water/methanol. These conditions were held for $8 \mathrm{~min}$ and then initial conditions were reestablished within $0.1 \mathrm{~min}$ and kept for $4.9 \mathrm{~min}$ before the next analysis started. The temperature of the column oven was set to $30{ }^{\circ} \mathrm{C}$. Mass spectra were acquired at a capillary temperature of $320^{\circ} \mathrm{C}$ and spray voltages of $4 \mathrm{kV}$ and $-3 \mathrm{kV}$ in positive and negative ionization modes, respectively. This method was adapted from previous studies (Achermann et al., 2018b).

The samples were first measured in full scan mode at a resolution of 140,000 at $\mathrm{m} / \mathrm{z} 200$ and a scan range of $50-750 \mathrm{~m} / \mathrm{z}$ in positive and negative switching mode. In a second injection, data-dependent MS2 spectra were recorded at a resolution of 17,500 at $200 \mathrm{~m} / \mathrm{z}$ (isolation window of $1 \mathrm{~m} / \mathrm{z}$ ) using an inclusion list of masses corresponding to suspected TPs. This list was compiled using previously found TPs in the literature, the EAWAG pathway prediction system (EAWAG-BBD, 2020) and by manually applying a range of plausible atomic modifications (hydroxylation, dihydroxylation, demethylation, dehydrogenation, hydrogenation, decarboxylation, etc.).

\subsection{Transformation product identification and structure elucidation}

A suspect TP screening was performed using the software Compound Discoverer 3.1. (Thermo Scientific). The first part of the workflow comprised retention time (RT) alignment (maximal RT shift: 2 min; mass tolerance $5 \mathrm{ppm}$ ) and peak picking (mass tolerance $5 \mathrm{ppm}$, minimal intensity 10,000, maximal peak width: $0.5 \mathrm{~min}$ ). Then, a subset of features was selected based on comparison with the predefined suspect list. Transformation product candidate peaks had to fulfil the following criteria to be selected for further analysis:

1. Intensity above a certain threshold: maximum area $>25,000$.

2. The peaks had to have a reasonable peak shape.

3. If a chemical formula was proposed, the observed isotopic pattern had to match the theoretical one.

4. If a MS2 spectrum was available, the fragmentation prediction and the matches to the fragments of the respective parent compound were taken into account. Besides, the FISh scoring node of Compound Discoverer 3.1. was used, rejecting compounds with a score below 50 .

5. The peak area of the TPs had to be at least 10 times higher in the effluent than in the influent of the reactor.

Structure elucidation was conducted with Compound Discoverer 3.1. software or manually based on the interpretation of the exact masses, the isotopic pattern of the MS spectra and the MS2 fragments. The outcome and confidence of the structural interpretation differed depending on the availability of structural evidence. To communicate the confidence in the structural interpretation, confidence levels were assigned as proposed by Schymanski et al. (2014): Level 5 (exact mass), Level 4 (unequivocal molecular formula), Level 3 (tentative candidates), Level 2 (probable structure) and Level 1 (confirmed structure). TP evidence, i.e., observed changes in molecular formula and structure, was used to assign corresponding reaction types to the OMPs.

\subsection{Calculations of reactor performance}

Several indicators were calculated to characterize reactor performance, including the net activated sludge produced, the endogenous biomass decay rate, the nitrogen oxidized, the recirculation ratio and the oxygen requirements.

The net waste activated sludge produced was estimated assuming typical heterotrophic parameters of biomass yield $\left(\mathrm{Y}=0.4 \mathrm{~g}_{\text {biomass }}\right.$ $\left.\mathrm{g}_{\text {substrate }}^{-1}\right)$, endogenous decay coefficient $\left(\mathrm{k}_{\mathrm{d}}=0.1 \mathrm{~d}^{-1}\right)$ and cell debris fraction $\left(f_{d}=0.15\right)$ (Metcalf and Eddy, 2014), as shown in Eq. (1):

$P_{X, V S S}=\frac{Y Q\left(S_{0}-S\right)}{1+\left(k_{d}\right) S R T}+\frac{\left(f_{d}\right)\left(k_{d}\right) Y Q\left(S_{0}-S\right) S R T}{1+\left(k_{d}\right) S R T}$

where:

$S_{0}$ influent COD concentration $\left(\mathrm{g} \mathrm{L}^{-1}\right)$

$\mathrm{S}$ effluent COD concentration $\left(\mathrm{g} \mathrm{L}^{-1}\right)$

The endogenous decay rate of biomass in the reactor was also estimated, as indicated in Eq. (2):

$r d=-\mathrm{kd} \cdot \mathrm{X}_{\mathrm{VSS}}$

with:

$\mathrm{X}_{\mathrm{VSS}}$ biomass concentration in the bioreactor $\left(\mathrm{g} \mathrm{L}^{-1}\right)$

Moreover, as shown below (Eq. (3)), the oxidized nitrogen was calculated:

$N_{o x}=T K N_{0}-N-\frac{0.12 P_{X, V S S}}{Q}$

with: 
$N_{o x} \quad$ nitrogen oxidized $\left(\mathrm{mg} \mathrm{L}^{-1}\right)$

$T K N_{O}$ influent total Kjeldahl nitrogen $\left(\mathrm{mg} \mathrm{L}^{-1}\right)$

$N$ effluent $\mathrm{N}-\mathrm{NH}_{4}^{+}$concentration $\left(\mathrm{mg} \mathrm{L}^{-1}\right)$

$\mathrm{P}_{\mathrm{X}, \mathrm{VSS}}$ biomass as VSS wasted $\left(\mathrm{mg} \mathrm{d}^{-1}\right)$

$\mathrm{Q}$ influent flow $\left(\mathrm{L} \mathrm{d}^{-1}\right)$

To maintain a constant biomass concentration in the reactor, purge was performed daily. Besides, biomass recirculation was performed in a ratio close to 1, typical for activated sludge systems (Metcalf and Eddy, 2014), as indicated in Eq. (4):

$R=\frac{1-\left(\frac{H R T}{S R T}\right)}{\left(\frac{X_{R}}{X_{V S S}}\right)-1}$

with:

$\mathrm{X}_{\mathrm{R}}$ biomass concentration in the settler $\left(\mathrm{g} \mathrm{L}^{-1}\right)$

To ensure aerobic conditions, the dissolved oxygen (DO) concentration was controlled. Experimental values over $5 \mathrm{mg} \mathrm{O}_{2} \mathrm{~L}^{-1}$ were always maintained in the reactor, following the guidelines of Metcalf and Eddy (2014) for aerobic biological systems during wastewater treatment. The oxygen provided was sufficient to fully oxidize the influent COD (Eq. (5)).

$R_{0}=Q\left(S-S_{0}\right)-1.42 P_{X, V S S}=1.8 \mathrm{~g} \mathrm{O}_{2} d^{-1}$

\section{Results and discussion}

\subsection{Reactor performance}

The reactor was operated for 28 days and steady-state conditions were achieved after one week (Table S3). During experimentation, neutral $\mathrm{pH}$ was maintained to maximize the activity of the microorganisms as well as to avoid any effects of varying $\mathrm{pH}$ levels on OMPs removal. Although frequently receiving little attention, $\mathrm{pH}$ is a key parameter affecting OMPs biotransformation. Its increase by just one unit $\mathrm{pH}$ can considerably promote the removal of OMPs with cationic-neutral specification and hinder that of compounds with neutral-anionic speciation, as shown by Gulde et al. (2014).

Biomass concentration remained quite stable at $1.4 \mathrm{~g} \mathrm{~L}^{-1}$ by controlling the purge (Fig. 1), performed almost daily from the settler, and the control of the recirculation, set at a ratio of $100 \%$ of the influent flow (Eq. (4)). The source of organic matter was acetate, which was fully consumed (95-100\%), leading to effluent COD concentrations consistently below $0.03 \mathrm{~g} \mathrm{~L}^{-1}$ (Fig. 1). Besides, operation occurred in the absence of nitrification (Fig. 1), indicating that all the nitrogen consumed was used only for microbial growth. In the non-consumed nitrogen, some soluble non-degradable organic nitrogen from endogenous respiration may have been present.

The net waste activated sludge produced was estimated at $0.15 \mathrm{~g}$ VSS L $^{-1}$ (Eq. (1)), including the active heterotrophic biomass formed daily and the cell debris, which accounts for $10-20 \%$ of the decayed biomass and cannot be degraded due to their extremely low hydrolysis kinetics (Liu and Wang, 2015). Moreover, there was also an endogenous decay rate of biomass in the reactor, proportional to the active biomass concentration ( $\mathrm{X}_{\mathrm{VSS}}$ ), that accounted for $0.14 \mathrm{~g} \mathrm{VSS} \mathrm{L}^{-1} \mathrm{~d}^{-1}$ (Eq. (2)). The endogenous decay represents the cell biomass loss and includes an internal decay (cell level), involving the oxidation of stored substrates to produce energy for cell maintenance, and an external decay (community level), such as cell death or predation by higher organisms (Liu and Wang, 2015). Our reactor presented mostly aerobic heterotrophic bacterial strains, as well as higher life-forms, such as rotifers and protozoans, based on microscopic observation. The high life forms have also been shown to participate in the removal of OMPs, as reported by Gulde et al. (2018) for protozoa, which seem to be involved in the ion
A)

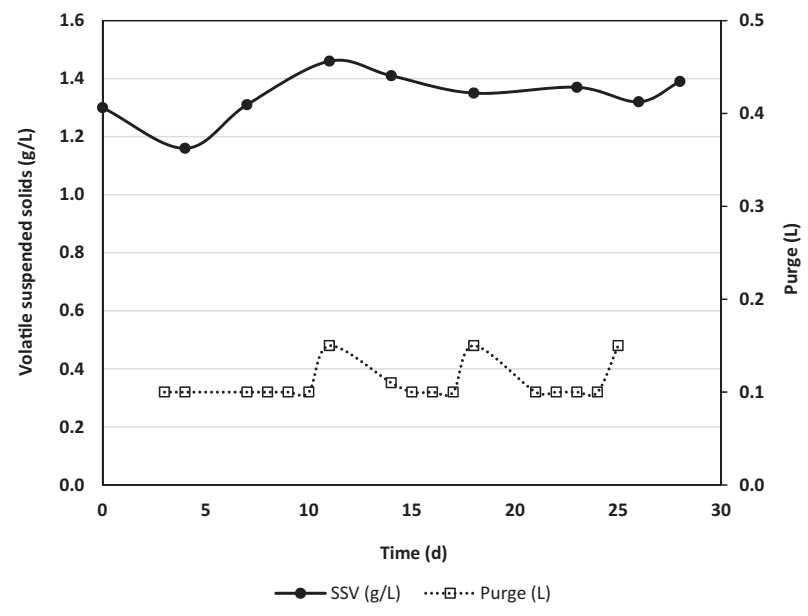

B)

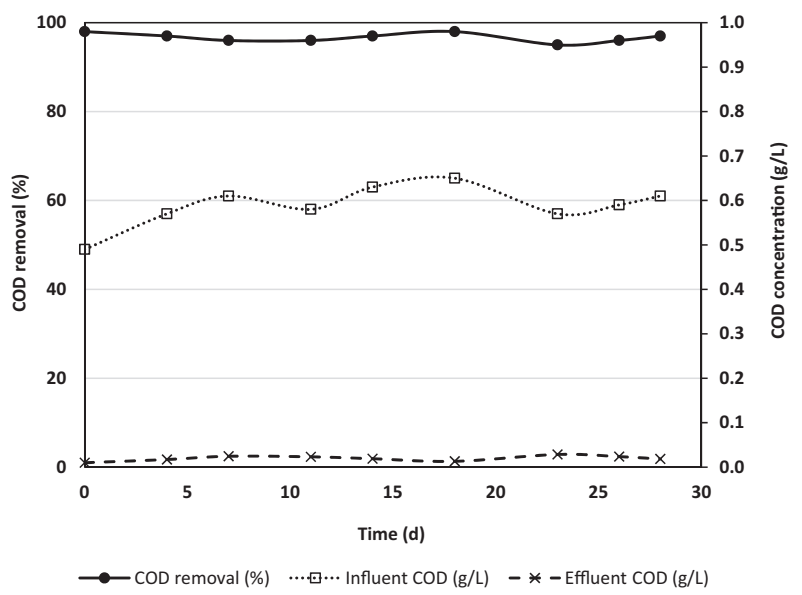

C)

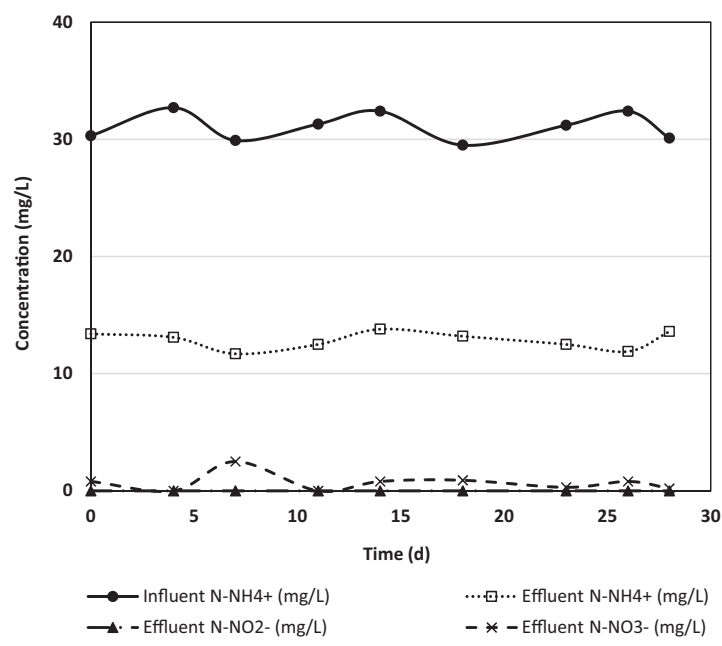

Fig. 1. Operational parameters obtained in the continuous aerobic heterotrophic reactor. A) VSS concentration and purge performed. B) COD removal along with COD influent and effluent concentrations. C) Influent $\mathrm{N}-\mathrm{NH}_{4}^{+}$and effluent $\mathrm{N}-\mathrm{NH}_{4}^{+}, \mathrm{N}-\mathrm{NO}_{3}^{-}$and $\mathrm{N}^{-\mathrm{NO}_{2}^{-}}$ concentrations. 
trapping of amine-containing compounds and the hydrolysis of select esters and phenylurea compounds.

\subsection{Heterotrophic OMPs biotransformation in activated sludge systems}

Fig. 2 shows the fate of the selected OMPs in the continuous heterotrophic reactor. Sorption appears to be minimal for most compounds $(<10 \%$ ), except for FLX, for which it accounts for $15-20 \%$ of the total mass balance. Results show that 17 out of the 20 OMPs were highly removed (above $80 \%$ ) due to heterotrophic activity and only 3 compounds were slightly (TMP) or not removed at all (CBZ, DZP). These results agree with the biotransformation observed in activated sludge units (Alvarino et al., 2014; Luo et al., 2014; Petrie et al., 2014), except for DCF, for which we obtain higher values than under typical activated sludge conditions (Alvarino et al., 2014; Fernandez-Fontaina et al., 2016). Nonetheless, in other biological treatments high DCF efficiencies have also been achieved, as in a hybrid biofilm-activated sludge process (Jewell et al., 2016b) and in a nitrifying moving bed biofilm reactor (Torresi et al., 2016). In our experiments, DCF was biotransformed rather extensively, i.e., at 80\% (Fig. 2), which could indicate the presence of certain heterotrophic genera capable of biotransforming it more efficiently. In this regard, Nguyen et al. (2019) showed that under exposure to a primary carbon substrate and DCF, certain genera of activated sludge bacteria can significantly increase their abundance, suggesting that they might gain a competitive advantage from its cometabolic removal.

To understand the variability in OMPs biotransformation reported in the literature, Fig. 3 compares the biotransformation performance of our aerobic heterotrophic reactor with that reported under nitrifying conditions exclusively (systems not fed with organic carbon or that have inhibited the heterotrophic activity) and in activated sludge systems presenting both heterotrophic and nitrifying activities. Firstly, it can be observed that heterotrophs reach biotransformations similar to the values of activated sludge plants, indicating that they can greatly contribute to OMPs removal, and that, for certain compounds, there may not be the need to set up WWTPs with nitrifying activities. There is only a very limited number of studies evaluating the biotransformation of the selected OMPs with exclusively nitrifying populations. In such works, they have also reported high removals for these compounds, indicating that both nitrifiers and heterotrophs have in their metabolic networks enzymes capable of biotransforming the OMPs. However, there are a few compounds that show variations in their behavior between the different conditions. While biotransformation of SMX and TCS is clearly higher under heterotrophic or activated sludge conditions, CBZ and DZP show better efficiencies with nitrifying populations. Moreover, although the average removal values of TMP seem similar under all conditions, it is a compound typically difficult to remove by aerobic heterotrophs (Fernandez-Fontaina et al., 2016), while some nitrifying populations have shown the capacity to biotransform it up to $50 \%$ or more (Batt et al., 2006; Fernandez-Fontaina et al., 2012). Furthermore, as discussed previously, heterotrophs display better biotransformation for DCF. Additionally, it is surprising to observe higher average biotransformations for some compounds under exclusively heterotrophic or nitrifying conditions than in activated sludge systems presenting both activities. A possible explanation could be due to differences in process conditions under which the experiments were performed, such as applying different organic loading rates. However, previous studies have shown that, in certain cases, mixed consortia of bacteria can provide worse OMPs removals than individual populations because the composition of a mixed bacterial culture can affect their performance (Larcher and Yargeau, 2011).

Thus, based on Fig. 3, it can be concluded that nitrifying systems or nitrifying activated sludge systems would not be required to achieve the typical biotransformation extents of the selected OMPs since, in general, the biotransformation is similar for all microbial populations. Nonetheless, it is important to remark that the data collected from the literature was obtained from experiments performed at considerably different operational conditions, which could have affected the biotransformation extents obtained in each case and explain the high standard deviations observed for some compounds.

\subsection{Identification of enzymatic biotransformations of OMPs in aerobic het- erotrophic conditions}

In total, 12 TPs were confidently identified (Table 1 and Table S4) for the 20 investigated OMPs and assigned to three major types of transformation reactions (oxidation, hydrolysis and conjugation). For ADBI and FLX, 2 different TPs were observed, pointing towards sequences of transformation steps or transformations taking place at different functional groups. The structural confidence was considered probable (level 2) for 1 TP and tentative (level 3) for 9 TPs, whereas 2 TPs could only be assigned an unequivocal molecular formula (level 4). The

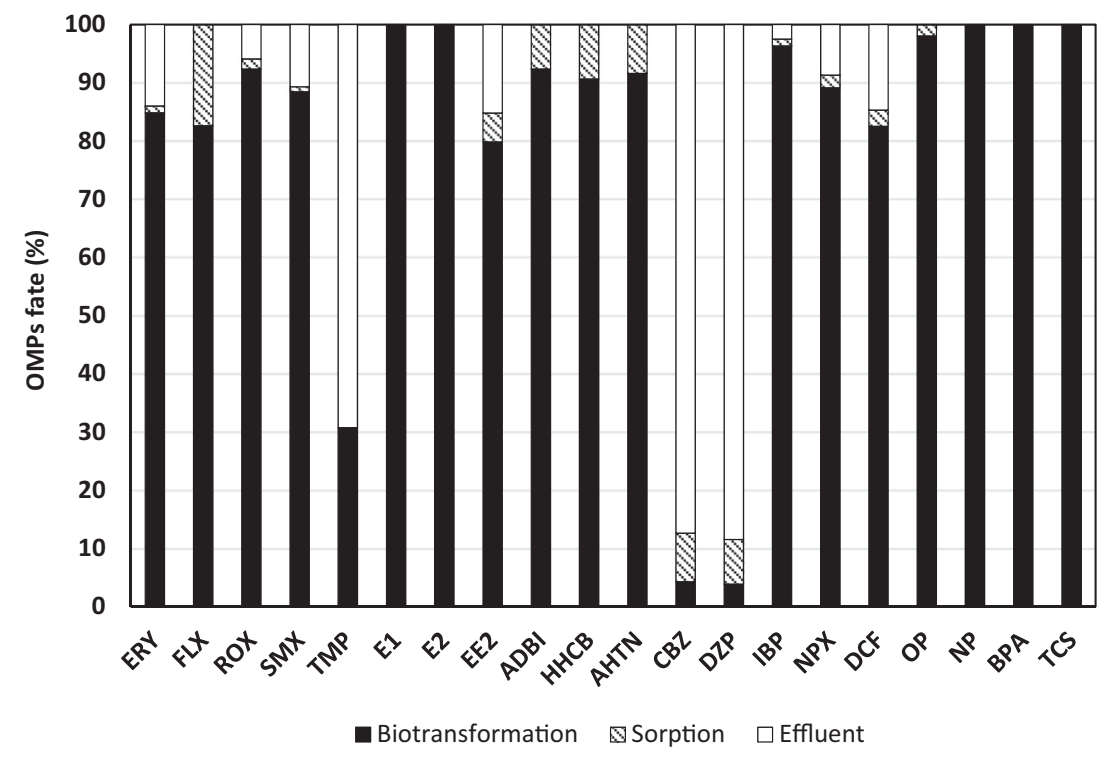

Fig. 2. Fate of the OMPs in the continuous aerobic heterotrophic reactor operated with fixed HRT (1 d) and OLR $\left(0.6 \mathrm{~g} \mathrm{COD} \mathrm{L}^{-1} \mathrm{~d}^{-1}\right)$. 


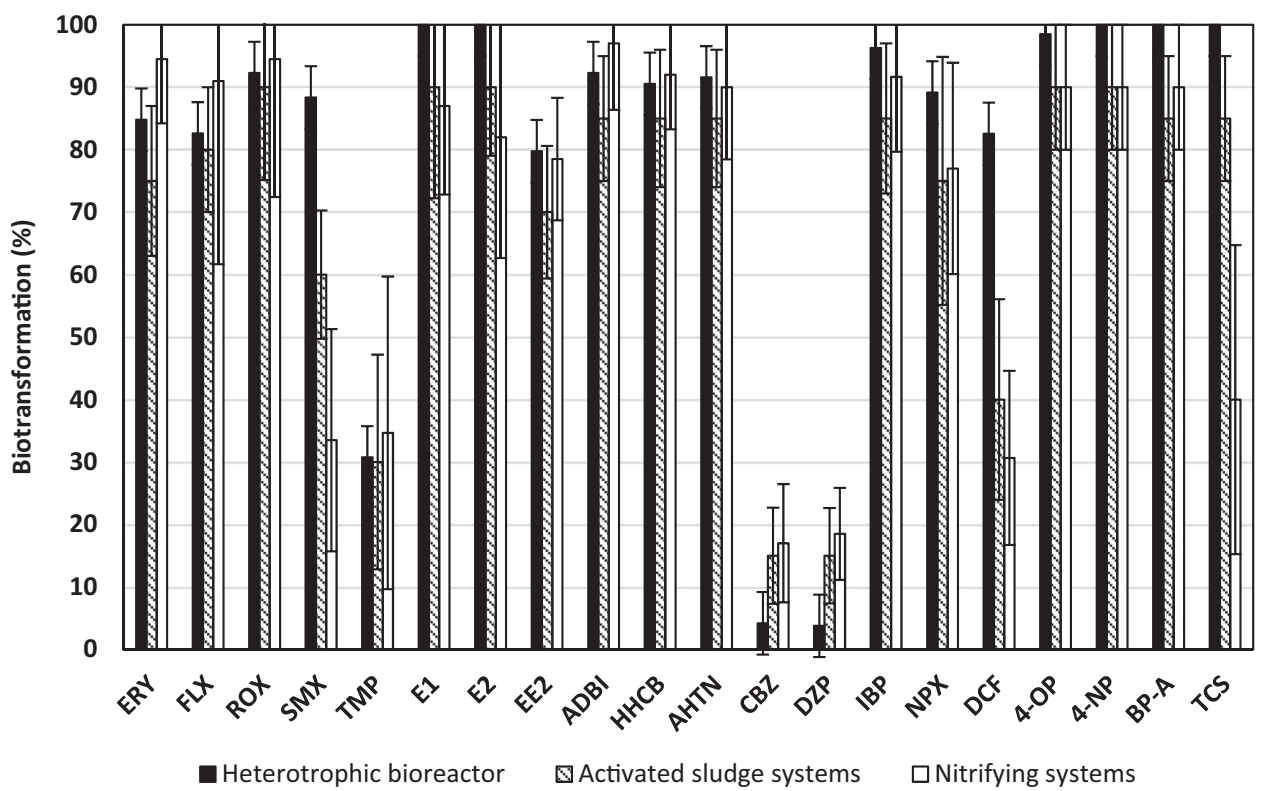

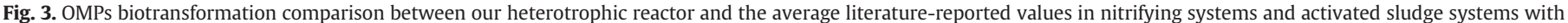
heterotrophic and nitrifying activities.

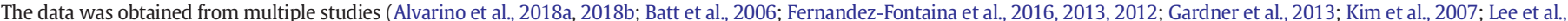
2015; Luo et al., 2014; Margot et al., 2015; Petrie et al., 2014; Suarez et al., 2010; Tran et al., 2018, Tran et al., 2009; Wang et al., 2020; Yi and Harper, 2007).

confidence varied mostly depending on the availability of MS and MS2 data, literature information and the molecular structure of the TPs and respective OMPs (structural assignments for TPs containing only $\mathrm{C}, \mathrm{H}$ and $\mathrm{O}$ atoms were generally treated with more caution).

\section{A. Oxidation}

Oxidation reactions frequently represent the initial biotransformation of xenobiotics in activated sludge systems. In our reactor, we determined several TPs that were formed through oxidative biotransformation, in the form of hydroxylation, deamination, demethylation and dehydrogenation.

\section{A.1. Hydroxylation}

Hydroxylation is commonly reported during OMPs biotransformation since it can be carried out by multiple microorganisms. For instance, AOB and AOA can hydroxylate mianserin (Men et al., 2016), the novel complete AOB (commamox), carbendazim (Han et al., 2019) and heterotrophic microorganisms, EE2 (Khunjar et al., 2011). Our results show heterotrophic hydroxylation of ADBI, HHCB, E1, E2, DCF and NP (Table 1), likely catalyzed by low specificity monooxygenases, such as cytochrome P450 or flavin-containing monooxygenases, or dioxygenases, such as Rieske-type non-heme-iron dioxygenases (Bjørseth and Angeletti, 1986). The most common biotransformation reaction of steroid hormones, including E1 and E2, is hydroxylation, performed by oxygenases in multiple organisms, such as bacteria, fungi or algae (Pratush et al., 2020). Fragrances can also undergo hydroxylation, as reported for HHCB, in bacteria, algae and fungi, where the initial biotransformation reaction is hydroxylation at different carbon positions (Ding et al., 2020; Martin et al., 2007). In the case of DCF, there is limited information about its biotransformation reactions in WWTPs. However, hydroxylation has been observed as the first reaction in its biotransformation pathway in activated sludge plants, being considered a bottleneck due to its low rate, which could explain the frequently limited removal yield (Bouju et al., 2016). In our reactor, DCF was highly biotransformed (Fig. 2) and the corresponding hydroxylated TP was found, possibly indicating that heterotrophs were able to perform the hydroxylation step efficiently. Differently to DCF, NP hydroxylation in
WWTPs has not been reported before, to the best of our knowledge. Nonetheless, in mammals and fish, hydroxylation both in the ring and the alky chain has been observed, possibly due to the action of cytochrome P450 enzymes (Thibaut et al., 2002).

\section{A.2. Deamination}

A TP detected for FLX (Table 1) was either (i) the product of deamination at the secondary amine group followed by oxidation of the resulting aldehyde or (ii) the outcome of initial demethylation, followed by deamination of the resulting primary amine TP and final oxidation of the formed aldehyde. The second pathway seems more plausible since secondary amines typically undergo dealkylation before oxidative deamination. Nonetheless, in certain cases, direct deamination of secondary amines may occur, as in the metabolism of propranolol, where the biotransformation can occur through the desisopropyl primary amine metabolite or by a direct oxidative deamination reaction yielding an aldehyde metabolite and isopropylamine (Beale and Block, 2011). Gulde et al. (2016) observed deaminations for some primary, secondary and tertiary OMPs, such as primaquine, $\mathrm{N}$-demethylvenlafaxine and pyrilamine, but they did not observe FLX deamination as in this study.

Assuming the previous demethylation, the deamination step in FLX could be performed by an amine oxidase, catalyzing the oxidative cleavage of the primary amine to an aldehyde while releasing ammonia and hydrogen peroxide. These enzymes are found in multiple organisms controlling the level of amines, participating in multiple pathways, and allowing various amine substrates to be used as sources of carbon and nitrogen in prokaryotes (Messerschmidt, 2010). The following oxidation of the aldehyde to the carboxylic acid is likely catalyzed by an aldehyde dehydrogenase, using oxygen from a water molecule and $\mathrm{NAD}^{+}$ or $\mathrm{NADP}^{+}$as cofactors, present in a broad range of anabolic and catabolic pathways and key in the elimination of endogenous and exogenous toxic aldehydes (Riveros-Rosas et al., 2019).

The hypothetical $N$-demethylation of the secondary amine of FLX would form seproxetine as a TP, the most important FLX active metabolite observed in humans and WWTPs. In human metabolism, the biotransformation occurs thanks to cytochrome P450 (Von Moltke et al., 1997), so likely a monooxygenase could be the responsible enzyme in the heterotrophic reactor. The conversion of FLX to seproxetine in 
D.M. Kennes-Veiga, B. Vogler, K. Finer et al.

Science of the Total Environment 780 (2021) 146564

Table 1

Summary of the suggested RPs structures found in the aerobic heterotrophic reactor, including the confidence level, atom changes relative to the parent IMPs and biotransformation reactions and enzymes likely involved in the process. The TP structures placed in brackets are only suggestions for possible structures. The functional groups bonded with dotted lines could be placed somewhere else in the molecule.

IMPs

Transformation product

Level

Atom change

Reaction

Candidate enzymes

ADBI

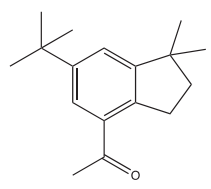

ADBI

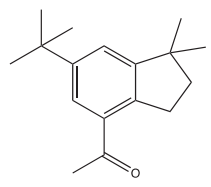

HHCB

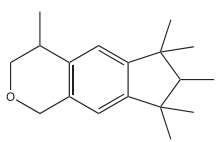

E1

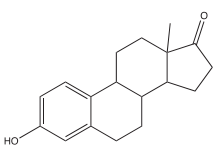

E2

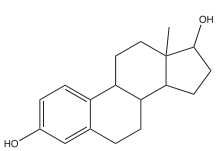

DEF

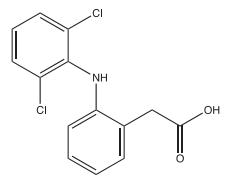

NP

TIP

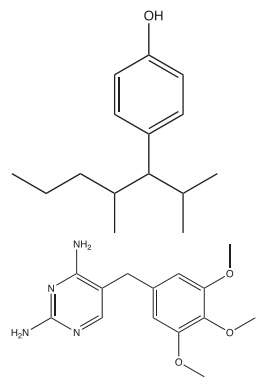

DIP

FIX

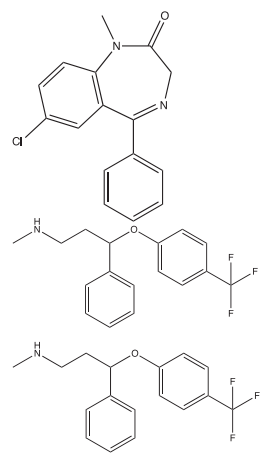

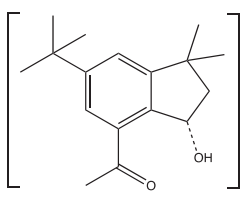

$+0$

Hydroxylation

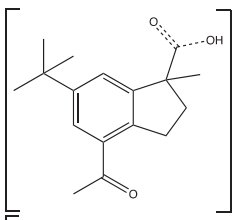

$+2 \mathrm{O}$

Additional oxidation

Hydroxylation

Hydroxylation

3

$+0$

Hydroxylation

Hydroxylation

Hydroxylation Additional oxidation

Hydrolysis

Demethylation

EC 1.14.-

3

- C, $2 \mathrm{H}$

Demethylation

Deamination

Oxidation

Conjugation

Conjugation

EC 1.14.-

EC 1.13.-

EC 1.13.-

EC 1.1.-

EC 1.14.-

EC 1.13.-

EC 1.14.-

EC 1.13.-

EC 1.14.-

EC 1.13.-

EC 1.14.-

EC 1.13.-

EC 1.1.-

EC 3.5.99.-

2

$+4 \mathrm{C}, 3 \mathrm{O}, 4 \mathrm{H}$

$+7 \mathrm{C}, 4 \mathrm{~N}, 2 \mathrm{O}, 4 \mathrm{H}$

EC 2.5.

(continued on next page)

7 


\begin{tabular}{|c|c|c|c|c|c|}
\hline OMPs & Transformation product & Level & Atom change & Reaction & Candidate enzymes \\
\hline & & & & & EC 3.5.4.11 \\
\hline
\end{tabular}

activated sludge is very relevant since there is an enantioselectivity preference for (S)-FLX biotransformation. This event leads to $(S)$-seproxetine formation and $(R)$-FLX accumulation (unless enantiomerization processes take place), which for some microorganisms can be 10 and 30 times more toxic than (S)-FLX, respectively, and cause an overall increase in toxicity (Andrés-Costa et al., 2017).

\section{A.3. Demethylation}

Demethylations are catalyzed by demethylases from a variety of enzyme families, including monooxygenases (Robb et al., 2018) and dioxygenases (Fedeles et al., 2015). $\mathrm{N}$-demethylation is the most common reaction, performed by oxidative demethylases exploiting the weak $\mathrm{C}-\mathrm{H}$ bonds adjacent to amines and acting on the $\mathrm{N}$-methyl groups. During the process, an oxygen atom is inserted to the $\mathrm{C}-\mathrm{H}$ bond and then a spontaneous decomposition of the hydroxylated intermediate occurs, forming formaldehyde and a demethylated product. O-demethylation reactions can also occur, particularly during ether cleavage. $N$-demethylation of OMPs has been reported for several amines, such as pargyline, and $O$-demethylation has been observed in anaerobic conditions for venlafaxine (Falås et al., 2016) and in activated sludge for TMP, likely due to the action of monooxygenases (Jewell et al., 2016a; Krah et al., 2016).

Besides the possible demethylation of FLX to seproxetine previously mentioned, $N$-demethylation of the tertiary amine of DZP was detected (Table 1), leading to the formation of nordazepam, a very active metabolite with a long half-life that has been found in humans (Kosjek et al., 2012). In human metabolism, the enzyme carrying out the biotransformation is a cytochrome P450 (Luk et al., 2014), thus, it is likely that in our bioreactor a monooxygenase was also the responsible enzyme.

\section{A.4. Dehydrogenation}

Besides hydroxylation, further oxidations were seen for ADBI and NP (Table 1). They could have been catalyzed by alcohol dehydrogenases or oxidases (depending on the electron acceptor), capable to form the carboxylic acid moiety (Phale et al., 2019). These enzymes are present in many organisms, including bacteria, and play a crucial role in many metabolic pathways, as in the reversible reaction where acetaldehyde is converted to ethanol by alcohol dehydrogenase, a key step to regenerate the cofactors required for glycolysis.

\section{B. Hydrolysis}

Hydrolysis reactions are carried out by hydrolases, previously observed in activated sludge, as during the biotransformation of atenolol by bacterial amidohydrolases and azoxystrobin by protozoan hydrolases (Achermann et al., 2018b). The reported hydrolases in literature belong to several catalytic classes, including amidases, esterases, phosphatases and peptidases, among others (Krah et al., 2016). Here, we report for TMP a hydrolytic displacement of a primary amine moiety (Table 1), a novelty compared to reported TMP biotransformations, involving mostly demethylation and oxidation reactions (Jewell et al., 2016a). It is hypothesized that the TP formed through hydrolysis of the aminopyrimidine group of TMP (Table 1 ) could be obtained thanks to aminopyrimidine aminohydrolase (EC 3.5.99.-), involved in the metabolism of thiamine, a vitamin required by organisms from many life kingdoms of life, including bacteria (Lemmer and Nitschke, 1994).
Hydrolysis of amine moieties in OMPs is rather rare since they more often undergo $\mathrm{N}$-oxidation, $\alpha$-C-hydroxylation and conjugation reactions (Gulde et al., 2016). However, this type of biotransformation has been observed before, as in reactions involving chorismic acid (Ganem, 1995), a metabolite present in the shikimic acid pathway, followed by bacteria and other organisms for the biosynthesis of folates and aromatic amino acids.

\section{Conjugation}

Conjugation reactions are anabolic and catalyzed by transferases thanks to the presence of a functional group in the substrate that serves as the anchoring site for a molecule or moiety. Since these types of reactions can occur both with exogenous and endogenous substrates, they play a key role in the metabolism of xenobiotics (Testa and Krämer, 2008).

We observed a conjugation reaction at the amine group of SMX (Table 1), leading to a TP found by Achermann et al. (2018a) in the effluent of several WWTPs. The biotransformation pathway consists of a pterin conjugation, an oxidation and a final hydrolysis reaction. The enzymes involved could belong to the folic acid pathway, such as pterin deaminase and dihydropteroate synthase. If the folic acid synthesis is the responsible pathway, the biotransformation would be linked to bacterial growth and maintenance, which could explain the generally good biotransformation of SMX observed in various environments, including anaerobic, nitrifying and heterotrophic (Achermann et al., 2018a).

Besides, a FLX TP was also formed by conjugation at the amine moiety (Table 1 ), following an $\mathrm{N}$-acylation reaction ( $\mathrm{N}$-succinylation), suggesting $\mathrm{N}$-acyltransferases as the responsible enzymes (Gulde et al., 2016). N-acylation reactions are important in microbial xenobiotic metabolism, with $\mathrm{N}$-succinylation being particularly involved in the biotransformation of primary and secondary amines to secondary and tertiary amines, respectively.

\section{Conclusions}

This study highlights the relevant role of aerobic heterotrophs in the cometabolic biotransformation of OMPs, speaking to their capacity to contribute to the overall removal of OMPs in activated sludge plants and questioning the requirement of maintaining a nitrifying activity. In fact, this study shows that heterotrophs are able to achieve similar extents of biotransformation for the selected OMPs as those reported in several literature studies with activated sludge (with nitrifying, denitrifying and heterotrophic activities) and purely nitrifying systems. Based on the TPs produced, it was possible to identify the main reactions involved in OMPs biotransformation under aerobic heterotrophic conditions as follows: oxidation (hydroxylation, dehydrogenation, deamination and demethylation), hydrolysis and conjugation routes. An overall analysis of all results allows selecting mono- and dioxygenases, dehydrogenases, hydrolases and transferases as some of the main enzymatic activities likely responsible for OMPs biotransformation under heterotrophic conditions. Overall, this work highlights the relevant contribution of heterotrophs to OMPs removal, which are gaining importance in the conception of new WWTPs, and deepens the knowledge on their biotransformation mechanisms. 


\section{CRediT authorship contribution statement}

David M. Kennes-Veiga: Investigation, Writing - original draft, Formal analysis, Conceptualization. Bernadette Vogler: Methodology, Formal analysis, Writing - review \& editing. Kathrin Fenner: Validation, Visualization, Writing - review \& editing, Supervision. Marta Carballa: Validation, Visualization, Writing - review \& editing, Supervision, Project administration, Funding acquisition. Juan M. Lema: Validation, Visualization, Writing - review \& editing, Supervision, Project administration, Funding acquisition.

\section{Declaration of competing interest}

The authors declare that they have no known competing financial interests or personal relationships that could have appeared to influence the work reported in this paper.

\section{Acknowledgements}

This research was funded by the Spanish Government (Agencia Estatal de Investigación) through the COMETT project (CTQ2016 80847-R) and a PhD Xunta de Galicia Grant (ED481A-2018/113, David Kennes). Authors from Universidade de Santiago de Compostela belong to CRETUS Strategic Partnership (AGRUP2015/02) and to Galician Competitive Research Group (GRC ED431C 2017/29), which are cofunded by FEDER (EU).

\section{Appendix A. Supplementary data}

Supplementary data to this article can be found online at https://doi. org/10.1016/j.scitotenv.2021.146564.

\section{References}

Achermann, S., Bianco, V., Mansfeldt, C.B., Vogler, B., Kolvenbach, B.A., Corvini, P.F.X., Fenner, K., 2018a. Biotransformation of sulfonamide antibiotics in activated sludge: the formation of pterin-conjugates leads to sustained risk. Environ. Sci. Technol. 52, 6265-6274. https://doi.org/10.1021/acs.est.7b06716.

Achermann, S., Falås, P., Joss, A., Mansfeldt, C.B., Men, Y., Vogler, B., Fenner, K., 2018b. Trends in micropollutant biotransformation along a solids retention time gradient. Environ. Sci. Technol. 52, 11601-11611. https://doi.org/10.1021/acs.est.8b02763.

Achermann, S., Mansfeldt, C.B., Müller, M., Johnson, D.R., Fenner, K., 2020. Relating metatranscriptomic profiles to the micropollutant biotransformation potential of complex microbial communities. Environ. Sci. Technol. 54, 235-244. https://doi.org/ 10.1021/acs.est.9b05421.

Alvarino, T., Suarez, S., Lema, J.M., Omil, F., 2014. Understanding the removal mechanisms of PPCPs and the influence of main technological parameters in anaerobic UASB and aerobic CAS reactors. J. Hazard. Mater. 278, 506-513. https://doi.org/10.1016/j. jhazmat.2014.06.031.

Alvarino, T., Lema, J., Omil, F., Suárez, S., 2018a. Trends in organic micropollutants removal in secondary treatment of sewage. Rev. Environ. Sci. Biotechnol. 17, 447-469. https:// doi.org/10.1007/s11157-018-9472-3.

Alvarino, T., Suarez, S., Lema, J., Omil, F., 2018b. Understanding the sorption and biotransformation of organic micropollutants in innovative biological wastewater treatment technologies. Sci. Total Environ. 615, 297-306. https://doi.org/ 10.1016/j.scitotenv.2017.09.27.

Andrés-Costa, M.J., Proctor, K., Sabatini, M.T., Gee, A.P., Lewis, S.E., Pico, Y., KasprzykHordern, B., 2017. Enantioselective transformation of fluoxetine in water and its ecotoxicological relevance. Sci. Rep. 7. https://doi.org/10.1038/s41598-017-15585-1.

Batt, A.L., Kim, S., Aga, D.S., 2006. Enhanced biodegradation of lopromide and trimethoprim in nitrifying activated sludge. Environ. Sci. Technol. 40, 7367-7373. https:// doi.org/10.1021/es060835v.

Beale, J.M., Block, J.H., 2011. Organic Medicinal and Pharmaceutical Chemistry. 12th ed. Wolters Kluwer-Lippincott Williams \& Wilkins, Philadelphia (USA).

Berkner, S., Thierbach, C., 2014. Biodegradability and transformation of human pharmaceutical active ingredients in environmentally relevant test systems. Environ. Sci. Pollut. Res. 21, 9461-9467. https://doi.org/10.1007/s11356-013-1868-6.

Besha, A.T., Gebreyohannes, A.Y., Tufa, R.A., Bekele, D.N., Curcio, E., Giorno, L., 2017. Removal of emerging micropollutants by activated sludge process and membrane bioreactors and the effects of micropollutants on membrane fouling: a review. J. Environ. Chem. Eng. 5, 2395-2414. https://doi.org/10.1016/j.jece.2017.04.027.

Organic micropollutants in the aquatic environment. In: Bjørseth, A., Angeletti, G. (Eds.), Organic Micropollutants in the Aquatic Environment. Springer, Netherlands https:// doi.org/10.1007/978-94-009-4660-6.

Bouju, H., Nastold, P., Beck, B., Hollender, J., Corvini, P.F.X., Wintgens, T., 2016. Elucidation of biotransformation of diclofenac and 4'hydroxydiclofenac during biological wastewater treatment. J. Hazard. Mater. 301, 443-452. https://doi.org/10.1016/j. jhazmat.2015.08.054.

Celiz, M.D., Tso, J., Aga, D.S., 2009. Pharmaceutical metabolites in the environment: analytical challenges and ecological risks. Environ. Toxicol. Chem. https://doi.org/10.1897/ 09-173.1.

Ding, T., Li, W., Cai, M., Jia, X., Yang, M., Yang, B., Li, J., 2020. Algal toxicity, accumulation and metabolic pathways of galaxolide. J. Hazard. Mater. 384, 121360. https://doi. org/10.1016/j.jhazmat.2019.121360.

EAWAG-BBD (2020) Pathway Prediction System website (available at http://eawag-bbd. ethz.ch/predict/). (Accessed in July, 2020).

Falås, P., Wick, A., Castronovo, S., Habermacher, J., Ternes, T.A., Joss, A., 2016. Tracing the limits of organic micropollutant removal in biological wastewater treatment. Water Res. 95, 240-249. https://doi.org/10.1016/j.watres.2016.03.009.

Fedeles, B.I., Singh, V., Delaney, J.C., Li, D., Essigmann, J.M., 2015. The AlkB family of Fe(II)/ $\alpha$-ketoglutarate-dependent dioxygenases: repairing nucleic acid alkylation damage and beyond. J. Biol. Chem. https://doi.org/10.1074/jbc.R115.656462.

Fernandez-Fontaina, E., Omil, F., Lema, J.M., Carballa, M., 2012. Influence of nitrifying conditions on the biodegradation and sorption of emerging micropollutants. Water Res. 46, 5434-5444. https://doi.org/10.1016/j.watres.2012.07.037.

Fernandez-Fontaina, E., Pinho, I., Carballa, M., Omil, F., Lema, J.M., 2013. Biodegradation kinetic constants and sorption coefficients of micropollutants in membrane bioreactors. Biodegradation 24, 165-177. https://doi.org/10.1007/s10532-012-9568-3.

Fernandez-Fontaina, E., Gomes, I.B., Aga, D.S., Omil, F., Lema, J.M., Carballa, M., 2016 Biotransformation of pharmaceuticals under nitrification, nitratation and heterotrophic conditions. Sci. Total Environ. 541, 1439-1447. https://doi.org/ 10.1016/j.scitotenv.2015.10.010.

Fischer, K., Majewsky, M., 2014. Cometabolic degradation of organic wastewater micropollutants by activated sludge and sludge-inherent microorganisms. Appl. Microbiol. Biotechnol. 98, 6583-6597. https://doi.org/10.1007/s00253-014-5826-0.

Ganem, B., 1995. The hydrolysis of amines to alcohols: clues from chrorismate processing enzymes. Tetrahedron Lett. 35, 815-818.

Gardner, M., Jones, V., Comber, S., Scrimshaw, M.D., Coello-Garcia, T., Cartmell, E., Lester, J., Ellor, B., 2013. Performance of UK wastewater treatment works with respect to trace contaminants. Sci. Total Environ. 456-457, 359-369. https://doi.org/10.1016/j. scitotenv.2013.03.088.

Gulde, R., Helbling, D.E., Scheidegger, A., Fenner, K., 2014. PH-dependent biotransformation of ionizable organic micropollutants in activated sludge. Environ. Sci. Technol. 48, 13760-13768. https://doi.org/10.1021/es5037139.

Gulde, R., Meier, U., Schymanski, E.L., Kohler, H.P.E., Helbling, D.E., Derrer, S., Rentsch, D., Fenner, K., 2016. Systematic exploration of biotransformation reactions of aminecontaining micropollutants in activated sludge. Environ. Sci. Technol. 50, 2908-2920. https://doi.org/10.1021/acs.est.5b05186.

Gulde, R., Anliker, S., Kohler, H.P.E., Fenner, K., 2018. Ion trapping of amines in Protozoa: a novel removal mechanism for micropollutants in activated sludge. Environ. Sci. Technol. 52, 52-60. https://doi.org/10.1021/acs.est.7b03556.

Han, P. Yu, Y, Zhou, L, Tian, Z, Li, Z, Hou, L, Liu, M., Wu, Q, Wagner, M., Men, Y, 2019. Specific micropollutant biotransformation pattern by the Comammox bacterium Nitrospira inopinata. Environ. Sci. Technol. 53, 8695-8705. https://doi.org/10.1021/ acs.est.9b01037.

Helbling, D.E., Johnson, D.R., Honti, M., Fenner, K., 2012. Micropollutant biotransformation kinetics associate with WWTP process parameters and microbial community characteristics. Environ. Sci. Technol. 46, 10579-10588. https://doi.org/10.1021/es3019012.

Jewell, K.S., Castronovo, S., Wick, A., Falås, P., Joss, A., Ternes, T.A., 2016a. New insights into the transformation of trimethoprim during biological wastewater treatment. Water Res. 88, 550-557. https://doi.org/10.1016/j.watres.2015.10.026.

Jewell, K.S., Falås, P., Wick, A., Joss, A., Ternes, T.A., 2016b. Transformation of diclofenac in hybrid biofilm-activated sludge processes. Water Res. 105, 559-567. https://doi.org/ 10.1016/j.watres.2016.08.002.

Kennes-Veiga, D.M., Gónzalez-Gil, L., Carballa, M., Lema, J.M., 2020. The organic loading rate affects organic micropollutants' cometabolic biotransformation kinetics under heterotrophic conditions in activated sludge. Water Res. 189, 116587. https://doi. org/10.1016/j.watres.2020.116587.

Kim, J.Y., Ryu, K., Kim, E.J., Choe, W.S., Cha, G.C., Yoo, I.K., 2007. Degradation of bisphenol A and nonylphenol by nitrifying activated sludge. Process Biochem. 42, 1470-1474. https://doi.org/10.1016/j.procbio.2007.06.010.

Khunjar, W.O., MacKintosh, S.A., Skotnicka-Pitak, J., Baik, S., Aga, D.S., Love, N.G., 2011. Elucidating the relative roles of ammonia oxidizing and heterotrophic bacteria during the biotransformation of 17 alpha-ethinylestradiol and trimethoprim. Environ. Sci. Technol. 45, 3605-3612. https://doi.org/10.1021/es1037035.

Kosjek, T., Perko, S., Zupanc, M., ZanoŠki Hren, M., Landeka Dragičević, T., Žigon, D., Kompare, B., Heath, E., 2012. Environmental occurrence, fate and transformation of benzodiazepines in water treatment. Water Res. 46, 355-368. https://doi.org/ 10.1016/j.watres.2011.10.056

Krah, D., Ghattas, A.K., Wick, A., Bröder, K., Ternes, T.A., 2016. Micropollutant degradation via extracted native enzymes from activated sludge. Water Res. 95, 348-360. https:// doi.org/10.1016/j.watres.2016.03.037.

Lambropoulou, D.A., Nollet, L.M.L., 2014. Transformation products of emerging contaminants in the environment. Transformation Products of Emerging Contaminants in the Environment: Analysis, Processes, Occurrence, Effects and Risks. John Wiley and Sons Ltd, Chichester, United Kingdom https://doi.org/10.1002/9781118339558.

Larcher, S., Yargeau, V., 2011. Biodegradation of sulfamethoxazole by individual and mixed bacteria. Appl. Microbiol. Biotechnol. 91, 211-218. https://doi.org/10.1007/ s00253-011-3257-8.

Larcher, S., Yargeau, V., 2013. Biodegradation of $17 \alpha$-ethinylestradiol by heterotrophic bacteria. Environ. Pollut. 173, 17-22. https://doi.org/10.1016/j.envpol.2012.10.028. 
Lee, D.G., Cho, K.C., Chu, K.H., 2015. Removal of triclosan in nitrifying activated sludge: Effects of ammonia amendment and bioaugmentation. Chemosphere 125, 9-15. https://doi.org/10.1016/j.chemosphere.2014.12.085.

Lema, J.M., Suarez, S., 2017. Innovative Wastewater Treatment \& Resource Recovery Technologies: Impacts on Energy, Economy and Environment, Water Intelligence Online. IWA Publishing https://doi.org/10.2166/9781780407876.

Lemmer, H., Nitschke, L., 1994. Vitamin content of four sludge fractions in the activated sludge wastewater treatment process. Water Res. 28, 737-739. https://doi.org/ 10.1016/0043-1354(94)90155-4.

Liu, G., Wang, J., 2015. Modeling effects of DO and SRT on activated sludge decay and production. Water Res. 80, 169-178. https://doi.org/10.1016/j.watres.2015.04.042.

Liu, Y., Gu, J., Zhang, M., 2020. A-B Processes: Towards Energy Self-sufficient Municipal Wastewater Treatment. IWA Publising https://doi.org/10.2166/9781789060089.

Luk, S., Atayee, R.S., Ma, J.D., Best, B.M., 2014. Urinary diazepam metabolite distribution in a chronic pain population. J. Anal. Toxicol. 38, 135-142. https://doi.org/10.1093/jat/ bku001.

Luo, Y., Guo, W., Ngo, H.H., Nghiem, L.D., Hai, F.I., Zhang, J., Liang, S., Wang, X.C., 2014. A review on the occurrence of micropollutants in the aquatic environment and their fate and removal during wastewater treatment. Sci. Total Environ. 473-474, 619-641. https://doi.org/10.1016/j.scitotenv.2013.12.065.

Majewsky, M., Gallé, T., Zwank, L., Fischer, K., 2010. Influence of microbial activity on polar xenobiotic degradation in activated sludge systems. Water Sci. Technol. 62, 701-707. https://doi.org/10.2166/wst.2010.925.

Majewsky, M., Gallé, T., Yargeau, V., Fischer, K., 2011. Active heterotrophic biomass and sludge retention time (SRT) as determining factors for biodegradation kinetics of pharmaceuticals in activated sludge. Bioresour. Technol. 102, 7415-7421. https:// doi.org/10.1016/j.biortech.2011.05.032.

Margot, J., Rossi, L., Barry, D.A., Holliger, C., 2015. A review of the fate of micropollutants in wastewater treatment plants. Wiley Interdiscip. Rev. Water 2, 457-487. https://doi. org/10.1002/wat2.1090.

Margot, J., Lochmatter, S., Barry, D.A., Holliger, C., 2016. Role of ammonia-oxidizing bacteria in micropollutant removal from wastewater with aerobic granular sludge. Water Sci. Technol. 73, 564-575. https://doi.org/10.2166/wst.2015.514.

Martin, C., Moeder, M., Daniel, X., Krauss, G., 2007. Biotransformation of the Polycyclic Musks HHCB and AHTN and Metabolite Formation by Fungi Occurring in Freshwater Environments. 41, pp. 5395-5402. https://doi.org/10.1021/es0711462.

Men, Y., Han, P., Helbling, D.E., Jehmlich, N., Herbold, C., Gulde, R., Onnis-Hayden, A., Gu, A.Z., Johnson, D.R., Wagner, M., Fenner, K., 2016. Biotransformation of two pharmaceuticals by the Ammonia-oxidizing Archaeon Nitrososphaera gargensis. Environ. Sci. Technol. 50, 4682-4692. https://doi.org/10.1021/acs.est.5b06016.

Men, Y., Achermann, S., Helbling, D.E., Johnson, D.R., Fenner, K., 2017. Relative contribution of ammonia oxidizing bacteria and other members of nitrifying activated sludge communities to micropollutant biotransformation. Water Res. 109, 217-226. https:// doi.org/10.1016/j.watres.2016.11.048.

Messerschmidt, A., 2010. Copper metalloenzymes. Comprehensive Natural Products II: Chemistry and Biology. Elsevier Ltd, pp. 489-545 https://doi.org/10.1016/b978008045382-8.00180-5.

Metcalf \& Eddy, 2014. Wastewater Engineering: Treatment and Resource Recovery. 5th ed. McGraw-Hill, New York (USA).

Nguyen, L.N., Nghiem, L.D., Pramanik, B.K., Oh, S., 2019. Cometabolic biotransformation and impacts of the anti-inflammatory drug diclofenac on activated sludge microbial communities. Sci. Total Environ. 657, 739-745. https://doi.org/10.1016/j. scitotenv.2018.12.094

Petrie, B., Barden, R., Kasprzyk-hordern, B., 2014. A review on emerging contaminants in wastewaters and the environment: current knowledge, understudied areas and recommendations for future monitoring. Water Res. 72, 3-27. https://doi.org/10.1016/j. watres.2014.08.053.

Phale, P.S., Sharma, A., Gautam, K., 2019. Microbial degradation of xenobiotics like aromatic pollutants from the terrestrial environments. Pharmaceuticals and Personal Care Products: Waste Management and Treatment Technology Emerging Contaminants and Micro Pollutants. Elsevier Inc. https://doi.org/10.1016/B978-0-12816189-0.00011-1.
Pratush, A., Ye, X., Yang, Q., Kan, J., Peng, T., Wang, H., Huang, T., Xiong, G., Hu, Z., 2020. Biotransformation strategies for steroid estrogen and androgen pollution. Appl Microbiol. Biotechnol. https://doi.org/10.1007/s00253-020-10374-9.

Rasche, M.E., Hicks, R.E., Hyman, M.R., Arp, D.J., 1990. Oxidation of monohalogenated ethanes and n-chlorinated alkanes by whole cells of Nitrosomonas europaea. J. Bacteriol. 172, 5368-5373. https://doi.org/10.1128/jb.172.9.5368-5373.1990.

Rice, E.W., Baird, R.B., Eaton, A.D., Clesceri, L.S., 2012. Standard Methods for the Examination of Water and Wastewater. 22nd ed. American Public Health Association, American Water Works Association, Water Environment Federation, Washington (USA).

Riveros-Rosas, H., Julián-Sánchez, A., Moreno-Hagelsieb, G., Muñoz-Clares, R.A., 2019. Aldehyde dehydrogenase diversity in bacteria of the Pseudomonas genus. Chem. Biol. Interact. 304, 83-87. https://doi.org/10.1016/j.cbi.2019.03.006.

Robb, C.S., Reisky, L., Bornscheuer, U.T., Hehemann, J.H., 2018. Specificity and mechanism of carbohydrate demethylation by cytochrome P450 monooxygenases. Biochem. J. 475, 3875-3886. https://doi.org/10.1042/BCJ20180762.

Schymanski, E.L., Jeon, J., Gulde, R., Fenner, K., Ruff, M., Singer, H.P., Hollender, J., 2014. Identifying small molecules via high resolution mass spectrometry: communicating confidence. Environ. Sci. Technol. https://doi.org/10.1021/es5002105.

Shi, J., Fujisawa, S., Nakai, S., Hosomi, M., 2004. Biodegradation of natural and synthetic estrogens by nitrifying activated sludge and ammonia-oxidizing bacterium Nitrosomonas europaea. Water Res. 38, 2323-2330. https://doi.org/10.1016/j. watres.2004.02.022.

Suarez, S., Lema, J.M., Omil, F., 2010. Removal of Pharmaceutical and Personal Care Products (PPCPs) under nitrifying and denitrifying conditions. Water Res. 44, 3214-3224. https://doi.org/10.1016/j.watres.2010.02.040.

Ternes, T.A., Bonerz, M., Herrmann, N., Löffler, D., Keller, E., Lacida, B.B., Alder, A.C., 2005 Determination of pharmaceuticals, iodinated contrast media and musk fragrances in sludge by LC tandem MS and GC/MS. J. Chromatogr. A 1067, 213-223. https://doi.org/ 10.1016/j.chroma.2004.10.096.

Testa, B., Krämer, S.D., 2008. The biochemistry of drug metabolism - an introduction: part 4. Reactions of conjugation and their enzymes. Chem. Biodivers. 5, 2171-2336. https://doi.org/10.1002/cbdv.200890199.

Thibaut, R., Debrauwer, L., Perdu, E., Goksøyr, A., Cravedi, J.P., Arukwe, A., 2002. Regiospecific hydroxylation of nonylphenol and the involvement of CYP2K- and CYP2Mlike iso-enzymes in Atlantic salmon (Salmo salar). Aquat. Toxicol. 56, 177-190. https://doi.org/10.1016/S0166-445X(01)00204-1.

Torresi, E., Fowler, S.J., Polesel, F., Bester, K., Andersen, H.R., Smets, B.F., Plósz, B.G., Christensson, M., 2016. Biofilm thickness influences biodiversity in nitrifying MBBRs - implications on micropollutant removal. Environ. Sci. Technol. 50, 9279-9288. https://doi.org/10.1021/acs.est.6b02007.

Tran, N.H., Urase, T., Kusakabe, O., 2009. The characteristics of enriched nitrifier culture in the degradation of selected pharmaceutically active compounds. J. Hazard. Mater. 171, 1051-1057. https://doi.org/10.1016/j.jhazmat.2009.06.114.

Tran, N.H., Reinhard, M., Gin, K.Y.H., 2018. Occurrence and fate of emerging contaminants in municipal wastewater treatment plants from different geographical regions-a review. Water Res. 133, 182-207. https://doi.org/10.1016/j.watres.2017.12.029.

Von Moltke, L.L., Greenblatt, D.J., Duan, S.X., Schmider, J., Wright, C.E., Harmatz, J.S. Shader, R.I., 1997. Human cytochromes mediating N-demethylation of fluoxetine in vitro. Psychopharmacology 132, 402-407. https://doi.org/10.1007/ s002130050362.

Wang, Y., Fenner, K., Helbling, D.E., 2020. Clustering micropollutants based on initial biotransformations for improved prediction of micropollutant removal during conventional activated sludge treatment. Environ. Sci. Water Res. Technol. 6, 554-565. https://doi.org/10.1039/c9ew00838a.

Yi, T., Harper, W.F., 2007. The link between nitrification and biotransformation of $17 \alpha-$ ethinylestradiol. Environ. Sci. Technol. 41, 4311-4316. https://doi.org/10.1021/ es070102q.

Yu, Y., Han, P., Zhou, L.J., Li, Z., Wagner, M., Men, Y., 2018. Ammonia monooxygenasemediated cometabolic biotransformation and hydroxylamine-mediated abiotic transformation of micropollutants in an AOB/NOB coculture. Environ. Sci. Technol. 52, 9196-9205. https://doi.org/10.1021/acs.est.8b02801. 